\title{
EL CONFLICTO DE CONCIENCTA EN EL JUEZ ENRIQUE LÓPEZ ALBÚJAR
}

Jorge Lira Pinto*

\section{RESUMEN}

Un fallo emitido en el Perú en 1917 sobre el delito de adulterio con singulares características: el juez reconoce que el texto legal dispone que se sancione penalmente el adulterio, pero como no está de acuerdo con el mandato por las razones que expone en los considerandos de su fallo, absuelve a los acusados. El autor de dicha resolución judicial es nada menos que Enrique López Albujar, notable escritor peruano. No hay de por medio desconocimiento ni motivaciones banales; es simplemente un conflicto de conciencia.

Palabras clave: Adulterio, prevaricato, conflicto de conciencia.

\section{THE CUNFLICT OF CONSCIENCIE ON JUDGE ENRIQUE LOPEZ ALBUJAR}

\begin{abstract}
A judgment issued in Peru in 1917 related to an act of adultery with singulars characteristics: the judge recognizes that the ruling stipulates to criminally punish the adultery, however he does not agree with the mandate for the reasons set out on his judgment, and absolve the defendants. The author of that judicial order is nothing less than Enrique Lopez Albujar, notable Peruvian writer. There is not involved lack of awareness nor banal motivations. It is simply a conflict of conscience
\end{abstract}

Key words: Adultery, prevarication, conflict of conscience

\footnotetext{
* Jorge Lira Pinto descubrió el fallo y se encargó de su publicación junto con los comentarios que el lector tiene en sus manos. Lira es profesor de la UNIFÉ / en el curso de Derecho Constitucional Comparado. Es abogado con estudios de Maestria en Derecho Constitucional y en Gobernabilidad.

Recepción: 02-10-2012

Aceptación: 22-10-2012
} 


\section{INTRODUCCIÓN}

A continuación transcribimos una sentencia emitida por el gran cuentista nacional Enrique López Albújar que además de literato, fue abogado. Se desempeñó también como periodista y originalmente tuvo una intensa actividad política.

La sentencia revela la particular posición de López Albújar respecto al delito de adulterio (según el canon que seguía el Código Penal de 1862). El conflicto de conciencia que surge en él debe ser motivo de reflexión.

\section{FALLO EMITIDO POR EL ESCRITOR ENRIQUE LÓPEZ ALBUJAR EN UN JUICIO POR ADULTERIO}

En el juicio seguido por doña Sara Hidalgo de Peña contra don Sebastián Peña y doña María Astete de Castillo por el delito de doble adulterio, se ha expedido la siguiente sentencia:

Vistos y apreciando: que presentada la querella de fs 1 y admitida por auto de fs. 5, se formalizó el juramento de calumnia; que prestadas las instructivas de los acusados, se mandó recibir la causa a prueba por auto de fs. 17; que ofrecidas por la querellante en parte de prueba las cartas de fs. 32 a 39 , se las admitió como tal y se ordenó su reconocimiento, de cuyo mandato se pidió reposición por el acusado Peña, la que le fue denegada; que apelado este auto, se confirmó por el de vista de fs. 55 v.; que habiéndose reanudado la actuación de las pruebas interpuso el querellante Peña a fs. Prescripción; que declarada infundada ésta por auto de fs. 66 vuelta; que habiendo pretendido la querellante, no obstante haberse vencido el término probatorio, que se actuaran algunas de sus pruebas, su pretensión fue rechazada por auto de fs. 91, que se confirmó por el de vista de fs. $100 \mathrm{v}$; y considerando: que desde el punto de vista legal el adulterio está simplemente acreditado con las declaraciones de fs. 83 de la testigo Filomena Celis, quien por la circunstancia de haber sido empleada de Peña durante mucho tiempo, ha estado mejor que nadie en condición de conocer las intimidades del hogar en que servía, dándole, por consiguiente, fuerza de veracidad a su dicho; que aun cuando de las demás declaraciones no se desprende cargo alguno contra los acusados, pues todas se basan en simples referencias y conjeturas, éstas unidas a la de la testigo Celis, que ha dicho "que los ha visto (a los acusados) durmiendo en una misma habitación en donde no había sino una sola cama", constituyen según las 
reglas de la lógica prueba suficiente para deducir de ella el concubinato ilícito de los acusados; que si bien es cierto que la prueba conjetural sólo tiene como valor en el sumario, esto no puede referirse a juicios como el presente en el que no lo hay y el que por su tramitación especial se asemeja al juicio civil ordinario, en los que dicha clase de prueba debe ser apreciada con sujeción a las reglas de la crítica; que en cuanto a la prueba instrumental de fs. 22 a 39, consistente en las diecisiete cartas presentadas por la querellante, no existiendo en ellas ningún término o expresión que dernuestre claramente las relaciones ilícitas de los acusados, su mérito probatorio es impertinente, pues por ellas no se comprueba sino la plena confianza que tenía Peña, respecto de sus negocios, en la Astete, hecho que no repugna con la honestidad ni con las buenas costumbres, ni menos puede ser causa de apreciación desfavorable para los acusados; que en atención a lo actuado en este juicio y a lo prescrito en los artículos 264 y 265 del Código Penal, la única consecuencia legal sería la condena de los codelincuentes; pero considerando: que si el fin de la penalidad es el restablecimiento del orden social perturbado, cuando el hecho que sejuzga no lo perturba en realidad, la aplicación de la pena carece de objeto y se torna injusta; que como en el presente caso el hecho de que se trata es un adulteriohecho que oor su naturaleza a un orden privado e íntimo- invocar esa perturbacion como fundamento de castigo sería incurrir en una inconsecuencia y en una ironía, porque no puede haber alteración de orden social ahí donde el hecho que se juzga es tan común que a nadie escandaliza y de cuya complicidad o tolerancia todos son responsables; que si el fin del matrimonio es hacer vida común y reproducir la especie mediante un compromiso legal basado en la felicidad, el mejor medio de solución no es la pena sino el rompimiento del pacto o el perdón del ofendido, pues con aquella se mata toda esperanza de reconciliación -prevista por la ley- se destruye de hecho un hogar y se infama no solamente al culpable sino también a los hijos, que han de ver en todo momento en uno de sus padres la causa de su infamación, lo que es profundamente inmoral y disociador; que si el único perjudicado y directamente ofendido por el adulterio es el cónyuge del adúltero, razón por la que el ministerio público, personero de la sociedad, no interviene en esta clase de hechos, su comprobación no debería tener más fin que la indemnización de una obligación de hacer, contraída en virtud del

\footnotetext{
1 López Albújar juzgaba con el Código Penal de 1862, en vigencia entonces. Este señala en el Art. 264 que: "La mujer que cometa adulterio será castigada con reclusión en segundo grado. El codelincuente sufrirá confinamiento en el mismo grado". Y el Art. 265 establecía: "El marido que incurra en adulterio teniendo manceba en la casa conyugal, será castigado con reclusión en segundo grado; y confinamiento en primer grado, en el segundo caso".

En estos dispositivos encuadraba el delito. Cf. Código Penal Peruano (1862), Sección Octava, De los delitos contra la honestidad, Títulol, Del adulterio, Arts. 264 y 265. (R.E.C.)
} 
contrato civil, tácitamente celebrado, ella no puede ser materia de una sanción penal sino de la responsabilidad prevista en el artículo 213 del Código Civil; que desde que las prescripciones de nuestro Código Penal sobre el adulterio son anacrónicas, parciales y fruto de los prejuicios de las sociedades educadas en el concepto erróneo de la expiación del delincuente y en el sacramental del matrimonio, es deber del juez no aplicarlas para que así se deroguen y se imponga la necesidad de su reforma; que si tratándose de la pena de muerte, la práctica de nuestro tribunales de justicia, inspirados indudablemente en el sentimiento público, ha concluido por abrogarla, tratándose de la que le corresponde al adulterio no hay razón para no hacer con ella lo mismo; que la circunstancia de ser este delito redimible por el agraviado demuestra claramente que la sociedad no tiene mayor interés en castigar a los culpables, el juez, en todo caso no debe mostrarse más interesado que la sociedad misma, ni debe olvidar que el espíritu humano es un compuesto de flaquezas; que, por último, si en los retrasados e intolerables tiempos de la predicción evangélica el hombre más grande y más justo de la humanidad acogió y perdonó públicamente a las pecadoras a las adúlteras, condenarlas en estos tiempos de radiante civilización, en que todo se discute y se impugna, sería pretender enmendar la obra de Jesús y ofender el espíritu de justicia y de tolerancia del siglo;

Por estos fundamentos, administrando justicia a nombre de la Nación,

Fallo: absolviendo a los acusados Sebastián Peña y María Astete de Castillo del delito de doble adulterio.

Y por esta mi sentencia, definitivamente juzgado en primera instancia, así lo pronuncio, y firmo en Huánuco a los 29 días del mes de diciembre de 1917.(fdo) Enrique López Albújar.

Aquí termina la transcripción literal del texto. Se ha hecho tal cual fue publicado en el libro del que a continuación hacemos su ficha bibliográfica.

\section{FICHA BIBLIOGRÁFICA DE "MEMORIAS":}

Título del libro: "Memorias". Autor: Enrique López Albújar. Lima. 1963. Primera Edición. Impreso en los Talleres Gráficos Villanueva. 241 páginas.

El autor de la nota de pie de página es Raúl Estuardo Cornejo quien además hace un colofón y la bibliografía del López Albújar. El libro está prologado por Ciro Alegría. 


\section{EL AUTOR}

Enrique López Albújar fue un notable escritor peruano nacido en Chiclayo el 23 de noviembre de 1872 y fallecido en Lima el 6 de marzo de 1966.

Tuvo una vocación política inicial de la que al parecer declinó posteriormente sin que esto haya significado la pérdida de sus ideales. Además se desempeñó como periodista y a ambas ocupaciones se entregó con intensidad, realizando campañas de moralidad pública y atacando los grandes intereses del sector de la clase alta y media alta a la que estaba ligado familiarmente, por lo que fue marginado e incluso sufrió prisión por poco tiempo debido a un poema que publicó contra el General Cáceres (el Héroe de la Breña) que en ese entonces era Presidente del Perú.

Con pocas perspectivas para ejercer su profesión de abogado en su tierra natal buscó una plaza de Juez en algún otro lugar del naís y es así como llegó a Huánuco. En esta ciudad dictó la sentencia que hemos transcrito.

El fallo le rnstó a López Albújar tres meses de suspensión por el delito de Prevaricato. Así lo cuenta él mismo en sus Memorias "Y hasta llegué a saborear la amargura de una suspensión de tres meses, poniéndome al borde de renunciar al cargo y alejarme para siempre del Perú.

... ¿Era acaso, una injusticia o un abuso del superior, algo de que pudiera yo agarrarme para justificar mi insólita actitud de juez idealista e innovador? ¿No estaba saltante el prevaricato cometido por mí? ¿No me había detenido yo mismo a recalcarlo en uno de los considerandos de la sentencia? ¿No es prevaricar decir: "cierto que el adulterio está probado legalmente, pero como en el caso presente la ley es injusta, pues se trata de un hecho que a mi juicio no es delictuoso, me abstengo de aplicarla y absuelvo a los acusados?

A continuación agrega el siguiente párrafo que nos parece especialmente valioso visto desde la perspectiva ética.

"Tenía que resignarme, que someterme a las consecuencias que yo mismo habia provocado; sacrificarme en honor a mis principios, sin descender a la bajeza del arrepentimiento que habría maculado mi conciencia.

No iba a decirle a la Corte Suprema, como disculpa, que me había equivocado, ni a pedirles reconsideración a quienes por la fuerza de la rutina legalista están siempre 
obligados a no darla. Mi dignidad de hombre antes que la de juez valía para mí más que esa pena y los tres sueldos que con ella dejaba de percibir".

López Albújar aprovechó el tiempo de la suspensión para escribir un magnífico libro "Cuentos Andinos" que tuvo un gran éxito. Fue traducido a varios idiomas, entre ellos, el inglés. "El alemán, el japonés, el italiano, el portugués, el polaco $y$, hace poco, el francés y el israelita; libro tres veces editado y cuya venta me ha suplido con exceso los tres sueldos que dejé de percibir por la suspensión" (López Albujjar, 1963, p 98). Señaló además con respecto a su mentada sentencia: "¿Hicebien? Don Quijote diría que sí. Panza diría que no."

Estuardo Cornejo, crítico literario especializado en la obra de López Albújar señala que el libro fue editado tres veces -1920, 1924 y 1950 -y todas las ediciones se agotaron. Al momento que se escribieron las memorias había hasta cuatro tesis universitarias sobre "Cuentos Andinos."

En una carta a Miguel de Unamuno le confesó "Yo no soy solo un cuentista, mi querido don Miguel, sino un perpetuo inadaptado, un rebelde. Vivo, pues en continuo vaivén entre el arte y la magistratura, inhibiéndome o desinhibiéndome, saltando del papel sellado a la cuartilla, del proceso al libro, de la dura y desconsoladora realidad a las ficciones de mi fantasía.

Este es mi drama, mi señor don Miguel." (Permítaseme una anotación personal. Conseguimos un ejemplar de las "Memorias" y de "Cuentos Andinos" en la última feria del libro en una librería de textos viejos. Para nuestra suerte, "Memorias" llevaba la dedicatoria y firma del propio autor).

\section{EL CONTEXTO DE LA SENTENCIA}

El propio Estuardo Cornejo se preocupó de anotar los artículos del Código Penal que López Albújar se negó a aplicar a partir del razonamiento expuesto en la sentencia que suscribió.

Sin embargo, para brindar mayores elementos de juicio, agregaremos algunas citas que nos parecen pertinentes.

Conviene recordar el Diccionario de García Calderón que desarrolla sus conceptos con el Código Penal vigente (el de 1862) en el momento de la resolución expedida por López Albújar. Sobre el tema se lee: "Adulterio. El 
acceso carnal que un hombre tiene con una mujer, siendo cualquiera de ellos, o ambos, casados con otras personas". Más adelante agrega "... El matrimonio impone a los cónyuges la obligación de guardarse fidelidad recíproca. (174. C). Esta obligación es tan positiva y eficaz, y tan persuadidos están de ella los esposos, que si una mujer llegase a concebir que más tarde no tendrá cabida en el corazón del que la pretende, renunciaría desde luego a su pretensión. Si la violación de un deber importa siempre un delito, es justo que el adulterio del marido, contrario á la fidelidad que debe a la mujer y al amor que le prometió, queden impune antela ley? (García Calderón, 1879, tomo I,p 63).

Si bien es cierto que la cita se refiere a la desigualdad en la pena impuesta por el Código Penal al adulterio de la mujer frente a la del hombre, hay un comentario -resaltado por nosotros- que nos parece interesante y es el referido al castigo a la infidelidad que no es cuestionado por el jurista García Calderón.

En su misma obra García Calderón, sobre el prevaricato, dice "EI prevaricatu es un delito que se comete por los empleados del poder judicial, y por lo abogados y procuradores y otras personas que intervienen en la administración de justicia.. "Lometen prevaricato: $1^{\circ}$ el Juez que expide sentencia definitivamente injusta; el Juez que conoce en causa que patrocinó como abogado: $3^{\circ}$ el Juez que cita hechos o resoluciones falsas: $4^{\circ}$ el Juez que se niega a juzgar, bajo pretex to de oscuridad o insuficiencia de la ley; $5^{\circ}$ El Juez que se apoya en leyes supuestas o derogadas (170. Pen.)

.. Los que incurran en los dos últimos delitos, serán condenados a suspensión, de tres a seis meses." (171. Pen.) (García Calderón, 1879 tomo 2, p 1585).

El Código Civil de 1852, vigente en el momento de la referida resolución señalaba que el adulterio de la mujer o el concubinato o la incontinencia pública del marido eran causal de divorcio (Art. 192 incs $1^{\circ}$ y $2^{\circ}$ ).

Había más causales pero nos hemos limitado a mencionar las pertinentes.

El mismo Código citado establecía en su Título Preliminar señalaba:

"Art. VIII.- Los jueces no pueden dejar de aplicar las leyes, ni juzgar sino por lo dispuesto en ellas.

Art. IX.- Los jueces no pueden suspender ni denegar la administración de 
justicia por falta, oscuridad o insuficiencia de la ley, en tales casos, resolverán atendiendo: $1^{\circ}$ al espíritu de la ley. $2^{\circ}$ a otras disposiciones sobre casos análogos; y $3^{\circ}$ a los principios generales del derecho..."

Cornejo Chávez sobre el adulterio menciona "Desde el punto de vista moral, el adulterio cometido por el marido es tan vituperable como el perpetrado por la mujer y puede influir igualmente con la ruptura del clima ético en que deben desenvolverse las relaciones conyugales" (Cornejo Chávez, 1972, p 272).

Finalmente citaremos en su parte pertinente el "Decálogo del Abogado" escrito por Ángel Osorio en su famoso libro "El Alma de la Toga" (Ossorio, 2003, p 281).

"I. No pases por encima de un estado de tu conciencia.

II. No afectes una convicción que no tengas."

\section{COMENTARIO FINAL} transcrito?

¿Hizo bien o mal Enrique López Albujar en la resolución que hemos

Pudo haber disimulado su posición sin modificar el resultado final de su veredicto merituando de modo distinto las pruebas ofrecidas y no lo hizo.

¿Cuál es límite interno del juez para no aplicar una norma en virtud del mandato de su conciencia?

Una pregunta central, al menos para nosotros, ¿en qué momento la negativa de un juez a aplicar una norma siguiendo la convicción de su conciencia se transforma en soberbia al pensar que "su verdad moral" está por encima de cualquier norma jurídica?

Otrosi: Es obvio que no abogamos por el adulterio. La sociedad debe evitarlo no solo por razones de un sano orden social sino también porque se debe preservar el valor de la fidelidad y de la lealtad. La transcripción de la resolución judicial no obedece a que estemos de acuerdo con ella sino a su indudable valor histórico al provenir de un narrador de alto valor literario que además fue un hombre con el que se puede discrepar pero al que no se le puede negar su integridad. 


\section{REFERENCIAS}

Cornejo Chávez, Héctor (1982) Derecho Familiar Peruano. 4 ta edición. Lima: Librería Studium.

García Calderón, Francisco (1879) Diccionario de la legislación peruana. Segunda edición. Paris.

López Albújar, Enrique (1963) Memorias. Primera edición. Lima: Talleres Gráficos PLV.

Ossorio, Ángel (2003) El alma de la Toga. Lima: Edit. San Marcos. 
